\title{
Exploring Cross Generational COVID-19 Attitudes and Behaviors
}

\author{
Regula H. Robnett ${ }^{*}$, Thomas M. Meuser ${ }^{2}$, Stephen Cheng', Dan Thai ${ }^{3}$, \\ Dechen Tuladhar ${ }^{3}$, McGyver Poulin4
}

${ }^{1}$ Center for Excellence in Aging and Health \& Occupational Therapy Department, University of New England, Portland, ME, USA

${ }^{2}$ Center for Excellence in Aging and Health \& School of Social Work, University of New England, Portland, ME, USA

${ }^{3}$ College of Medicine, University of New England, Portland, ME, USA

${ }^{4}$ Department of Occupational Therapy, University of New England, Portland, ME, USA

Email: ^rrobnett@une.edu

How to cite this paper: Robnett, R.H., Meuser, T.M., Cheng, S., Thai, D., Tuladhar, D. and Poulin, M. (2021) Exploring Cross Generational COVID-19 Attitudes and Behaviors. Advances in Aging Research, 10, 113-132.

https://doi.org/10.4236/aar.2021.105007

Received: August 12, 2021

Accepted: September 26, 2021

Published: September 29, 2021

Copyright (c) 2021 by author(s) and Scientific Research Publishing Inc. This work is licensed under the Creative Commons Attribution International License (CC BY 4.0)

http://creativecommons.org/licenses/by/4.0/

\begin{abstract}
Objective: The COVID-19 pandemic has presented extraordinary challenges that have tested the resolve of the world and transformed our daily lives. We sought to capture COVID-related attitudes and behaviors of older adults and relate these to views of adolescents from a national study in the USA. Methods: This mixed-methods online survey accepted responses from adult volunteers, age $55+$, from April to July $2020(\mathrm{~N}=223)$. We used a snowball approach to recruitment initiated in the state of Maine (USA). Results: Older respondents tended to report congruent attitudes concerning COVID-19 risks and associated preventative behaviors. Most reported taking Centers for Disease Control and Prevention guidance seriously. In contrast, adolescents surveyed in a prior study reported similar adherence, but less concern. Thematic review of open-ended responses highlights key intergenerational similarities and differences. Discussion: COVID-19 has changed day-to-day life in myriad ways. Attitudes vary within and between age groups. Further research could focus on intergenerational differences in motivations underlying behaviors as well as differing needs for public health education and support.
\end{abstract}

\section{Keywords}

COVID-19 Virus, Older Adults, Attitudes, Behaviors, Pandemic

\section{Exploring Cross Generational COVID-19 Attitudes and Behaviors}

Most would agree that significant changes in human relating and wellness have occurred as the global pandemic, known as the Coronavirus or COVID-19, has 
infected our lives. The pandemic spread quickly and killed well over a million people in less than a year. According to the Centers for Disease Control and Prevention (CDC), advanced age is a key risk factor for this disease [1]. In the USA, approximately 8 out of 10 deaths occurred in those aged 65 years or older. Those 85 and older are 13 times more likely to be hospitalized and 630 times more likely to die than adults aged 18 - 29 [1]. Researchers are working to understand COVID-19 related attitudes and behaviors across the lifespan, as responses to the pandemic may vary by locale, age, and life experience. The present study builds on important work with adolescent respondents completed early in the pandemic [2]. The relevance of examining age-related differences in public health initiatives is well established. For example, with respect to influenza prevention, it is important to consider both the age and health status (among other factors) of target populations, as younger persons often perceive less risk [3].

\section{Literature Review}

As of late fall, 2020, COVID-19 was spreading rapidly across the USA, with hospitalizations and deaths rising at alarming rates. Scientific understandings clashed with political and regional belief systems, and public health officials struggled to promote unified approaches to mask wearing, physical distancing, and other preventative measures. Expressed beliefs about the crisis and associated behaviors seemed influenced by group affiliation.

An early effort to understand such influences focused on adolescents: a group at low risk for physical harm from the virus but, arguably, at high risk for life disruption. Oosterhoff and Palmer added a new section on COVID-19 to an existing nationwide, online survey of adolescent health [2]. A total of 770 youths responded on measures of belief, attitude, and behavior in response to the emerging pandemic. Interesting associations between attitudes and behavioral responses emerged. Despite general agreement concerning the seriousness of the pandemic, respondents emphasized their own self-interest with respect to disease avoidance over a felt responsibility for the wellbeing of others. Just over $30 \%$ reported practicing social distancing with non-family members (female > male respondents), but $88 \%$ did report engaging in disinfecting behaviors multiple times per day. Those who viewed COVID-19 as more severe reported practicing more social distancing and more disinfecting behaviors, monitored the news more closely, and also reported more hoarding (e.g., food, toiletries). The Oosterhoff and Palmer study focused only on young people aged 13 to 18 who responded from the $20^{\text {th }}$ to the $22^{\text {nd }}$ of March 2020 [2]. Using the Oosterhoff and Palmer attitude and behavior study [2] as an example, we were interested in comparing older adults with adolescents using their data (with permission) as we had determined that this type of intergenerational comparison during the COVID-19 pandemic represented a gap in the literature.

A few studies have compared attitudes and behaviors between groups of people. Perrotta and colleagues [4] conducted a large international Facebook 
survey $(\mathrm{N}=71,612)$ in March and April 2020. They found significant differences between men and women in their perceptions of risk from the virus, confidence in the health care system, and their opinions about the likelihood of society following recommended preventative health measures. Women were more likely than men to report adopting mask wearing and practicing social distancing in the US subsample. The researchers also found that older adults perceived the virus as more serious and more threatening than younger adults. The rate of stockpiling of food and medicine was highest in the US (31\%) and lowest in the United Kingdom (18\%). Both women and older respondents tended to be more knowledgeable about COVID-19 and to view the pandemic as riskier and more serious to personal and public health [4].

In another early study, Wolf et al. [5] interviewed 630 adults (ages 23 to 88) in the Chicago area during the third week of March 2020. While all respondents were aware of the pandemic, only one-fourth were very worried about getting the virus and nearly one-third could not correctly identify symptoms or ways to prevent the virus. Intensive public education was just beginning, and some groups were more aware than others. Those age $70+$ and women tended to view the pandemic as more serious, but other groups at higher risk from the virus (e.g., those with three or more chronic conditions, those with lower socioeconomic status) expressed minimal concern. Overall, the perceived severity of the virus did increase over the course of the week that the study was conducted. In addition, people of color and those with lower health literacy believed they were less likely to get the virus than others. Interestingly, only $10 \%$ of respondents were "very confident" that the federal government could prevent a national outbreak [5].

Other studies examined age differences. Daoust conducted a study involving 72,417 people in 27 countries and found age-related differences in mask wearing and socially isolating behaviors, but these relationships were not linear. Whereas overall compliance with health recommendations remained flat across the ages (18 - 90+), mask wearing decreased by about $15 \%$ from age 20 to 60 and then decreased slightly more to age 80 after which compliance stabilized. Older adults were slightly less likely to use public transportation and gather in groups (although all effect sizes were small). Daoust hypothesized that the most vulnerable population (elders) would be more willing to self-isolate, but this was not found to be the case [6].

Findings from an open-access, web-based survey of 4676 adults by Canning et al. [7] revealed no significant differences in the likelihood of "going out" in older versus younger adults. Similar numbers of respondents expressed a willingness to venture into their communities. However, those over 50 reported less than half the number of close social contacts compared to younger adults, suggesting a different application of distancing guidelines between younger and older groups. Personal experience with the virus influenced behavior. Just over $20 \%$ of respondents reported having at least one symptom of COVID-19 in the past two weeks, primarily a cough. Interestingly, the researchers found that those reporting any shortness of breath were more likely to practice social distancing, but 
having a fever or a cough did not impact this behavior. Perhaps shortness of breath elicited more fear about personal wellness in these respondents. This survey was limited in its questioning, posing just a few key questions [7].

Age was a factor of concern as well in a study involving 1420 adults in Australia by Seale et al. [8], who found that older adults were more likely to adopt both hygiene and avoidance behaviors, as were females. A study by Czeisler et al. [9] involving 2402 respondents in the USA, also found an association with age in that older adults were more likely to adhere to the public health guidelines. Although the Seale study [8] was completed in March and the Czeisler study [9] took place in May, both reported similar outcomes. Also, the vast majority of respondents (well over 70\%) in both studies reported acceptance of and adherence to recommended avoidance and hygiene behaviors [8] [9].

Clearly, although thousands of people have been surveyed on a global scale, and a few tendencies have been demonstrated, no clear-cut age-associated delineations in COVID-19 attitudes and behaviors have been forthcoming. To our knowledge no study has examined specific attitudes and associated behaviors during the recent pandemic using two distinct cohorts. Oosterhoff and Palmer [2] through their very early study, offered this research team the opportunity to make these comparisons. Nor had any researchers, again to our knowledge, focused foremost on the attitudes and behaviors of older adults-the pandemic's most vulnerable group. A recently published article by Luo et al. (2021) [10] does include a cross generational comparison. However, this study had not yet been published when our study took place.

The early work by Oosterhoff and Palmer [2] offered this expert team in aging an opportunity to compare their teen responses and with those of older adults across a range of like items. We hypothesized that: 1) older adults would perceive COVID-19 as more serious than the adolescent population surveyed; and 2) older adults would report being more diligent about following preventative health behaviors.

Since mounting our survey, several other studies became available that informed our analysis. We developed additional hypotheses about older adults during data collection largely driven by the work of Perrotta et al. [4]:

1) Women tend to view COVID-19 as a more serious threat than men;

2) Those who downplay the seriousness of COVID-19 report engaging in fewer preventative health behaviors;

3) Those who view themselves as more conscientious practice more preventative health behaviors;

4) Those who view the pandemic as more serious tend to have more fear concerning the virus;

5) Those who have a higher level of fear about the virus tend to practice more preventative health behaviors.

\section{Methods}

The purpose of this mixed-methods study was to characterize, and then com- 
pare, attitudes and behaviors of older adults during the COVID-19 pandemic, using a sample of convenience. We intended to invite anyone aged 55 or over, who had an interest in the topic (similar to how Oosterhoff and Palmer [2] recruited adolescents). Our hope was that we could recruit hundreds of respondents. The study was approved by the Institutional Review Board (IRB) of the University of New England (UNE, \# IRB 041720-03). We asked for an expedited IRB review due to the time sensitive nature of our research. Respondents were recruited, initially, through the Legacy Scholars Program $(\mathrm{N}=500)$, adults age $55+$ years who support research and participate in a lifelong learning community associated with the UNE Center for Excellence in Aging and Health. We also recruited through email and word of mouth, resulting in "snowball" recruitment of older adults primarily in the northeast region of the USA.

The procedure of this study involved initially conferring with the Oosterhoff and Palmer team [2] to ensure that they were amenable to us using their data for comparison purposes. We then designed a survey that used many of their questions, sometimes changing questions as needed. For example, we omitted a question about parents' level of education and added a question about our respondents' level of education. Also, we determined that instead of asking about "hoarding" behavior we added the term "stockpiling." Recruitment took place through flyers, email, and word of mouth. Unlike the template study, we did not use social media, because many of the older adults in the area do not use social media and prefer email or hard copies of surveys.

\section{Measurement}

The research team developed a survey based on the Oosterhoff and Palmer survey for adolescents [2] to collect demographic information on respondents, a range of attitudes relevant to the growing pandemic (e.g., "How concerned are you about the coronavirus [COVID-19]"), and their perceived adherence to preventative health behaviors (e.g., mask wearing and physical distancing, as recommended by the CDC [1]). Respondents completed the survey online via REDcap, electronic data capture tools hosted at the University of New England.

Demographic questions were adopted from Oosterhoff and Palmer [2] and included political ideology and income as descriptors. Other items relevant to older adults were also utilized. These included Likert response items focused on interpersonal (e.g., social distancing, time with close others) and other protective behaviors (e.g., cleaning surfaces, stocking up on supplies, and handwashing). Prosocial attitudes (e.g., helping others in need) were also assessed. The current study used all the appropriate, comparable questions, and we added three qualitative open-ended questions addressing thoughts on social distancing, changes in daily routine, and giving respondents an opportunity to add other (final) thoughts.

Data were analyzed through descriptive statistics and difference tests, including Chi-Square, Independent Samples T-test, and the nonparametric Mann Whitney $U$ test $(p<0.05)$. There was no effort to control for multiple comparisons given the exploratory nature of this study. We describe the statistical analy- 
sis of quantitative responses in the following section, before describing the analysis of open-ended questions and respective results. Open-ended responses were analyzed via a team-based inductive coding process described further below.

\section{Results}

Respondents included 223 adults, 77\% female, and aged 54 - 97 years with a mean age of 71. Mean years of education was 17 (i.e., just beyond a bachelor's degree). The respondents were mostly Caucasian (95\%). The most common household size was two (52\%), while nearly one-third (32\%) reported living alone. Nearly $12 \%$ considered themselves conservative or very conservative, $29 \%$ considered themselves moderate, and 59\% listed being "liberal or very liberal."

About one-third were working at the beginning of the pandemic, and only $23 \%$ of these working respondents reported that their work status continued unchanged. Almost 85\% reported good financial security, having enough income to "buy not only the things they need, but also sometimes special things," or having enough money "to buy almost anything they want." Only one of the participants had reported being diagnosed with COVID-19, although seven reported having contracted the virus, and 29 thought they may have had it. Just over one-third $(37 \%)$ knew someone else who had been diagnosed in the first few months of the pandemic.

\section{Comparing to Adolescents}

We compared our sample of older adults' attitudes and health behaviors to those of the adolescents. The 770 adolescents in the Oosterhoff and Palmer study [2] were age $13-18$ with a mean of 16 years, currently in $9^{\text {th }}$ to $12^{\text {th }}$ grade. They were primarily female (72\%), and white (72.5\%). Most (53\%) came from families who, like the current older adults, had enough money to buy what they need and occasionally special things [2]. According to our initial hypotheses, we expected that the older adults would view the COVID-19 virus as more serious and that the older adults would also be more diligent about practicing preventative health behaviors. The first hypothesis that older adults viewed the virus as more serious was confirmed, as shown in Figure 1. Proportionately, far more older adults "strongly disagreed" that the corona virus was not serious or that it was "just the flu," compared to the adolescents in the Oosterhoff and Palmer study [2].

In examining the second original hypothesis, the comparison of adolescents' reported preventative health behaviors with this sample of older adults' behaviors is shown in Figure 2. While the current study changed the question about hoarding from Oosterhoff and Palmer study [2] to include stockpiling, no significant difference was found in this question, nor were differences found in questions about social distancing, or using hand sanitizer. Even behaviors that were statistically different tended to be close when rounded to whole numbers.

Opinions about others are shown in Figure 3. These are also similar between the two age-group samples with only two opinions being significantly different. Adolescents indicated that it was more important "to put your own needs before 
the needs of others" compared to elders. While neither group indicated it was important "to do what you want" regardless of others, elders placed slightly less

\section{PERCENT OF INDIVIDUALS THAT STRONGLY DISAGREE WITH THE STATEMENTS}

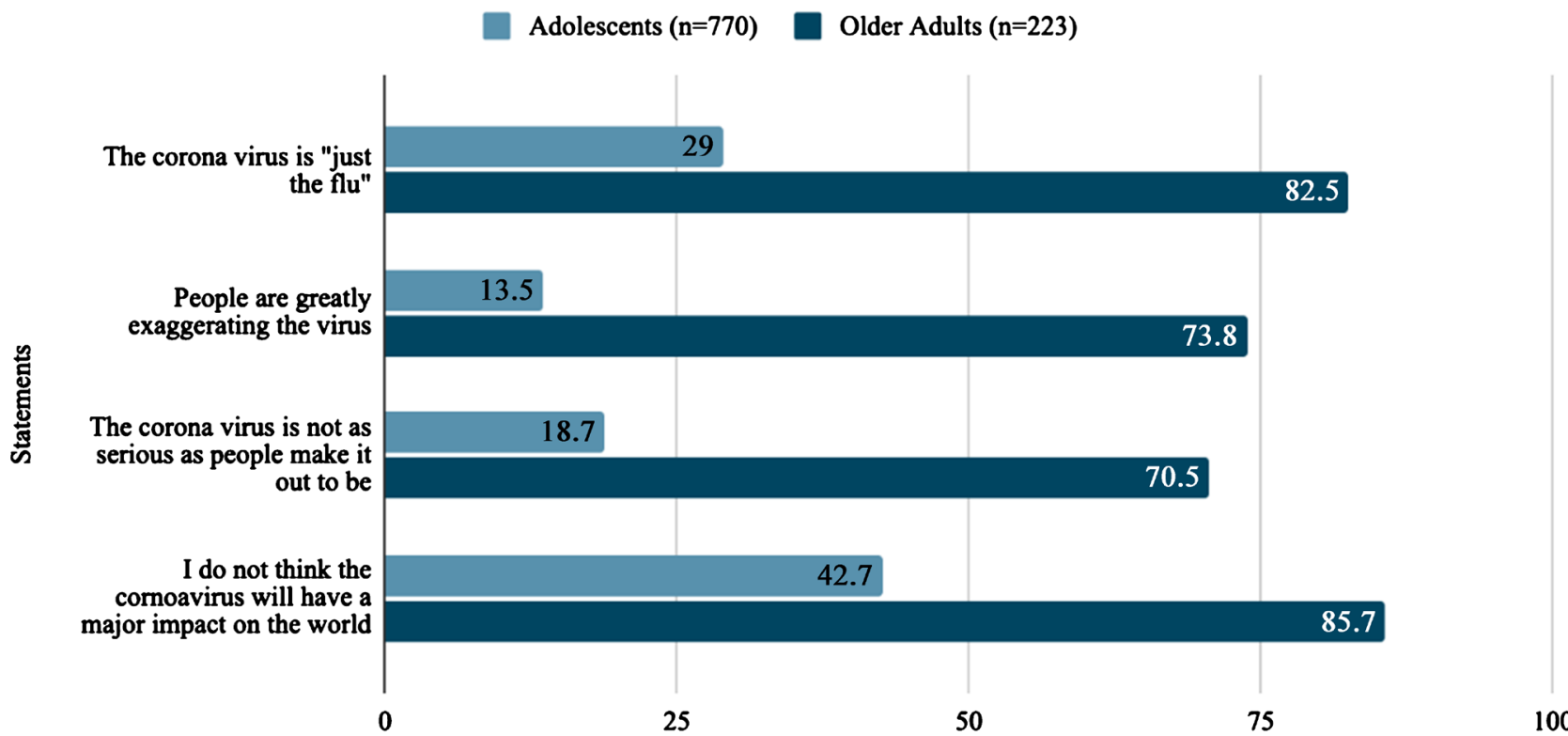

Percentage (\%)

Note: All opinions of the two age groups are significantly different at $\mathrm{p}<0.05$ level.

Figure 1. Percent of individuals that strongly disagree with the statements.

\section{BEHAVIOR FREQUENCY IN THE PAST WEEK}

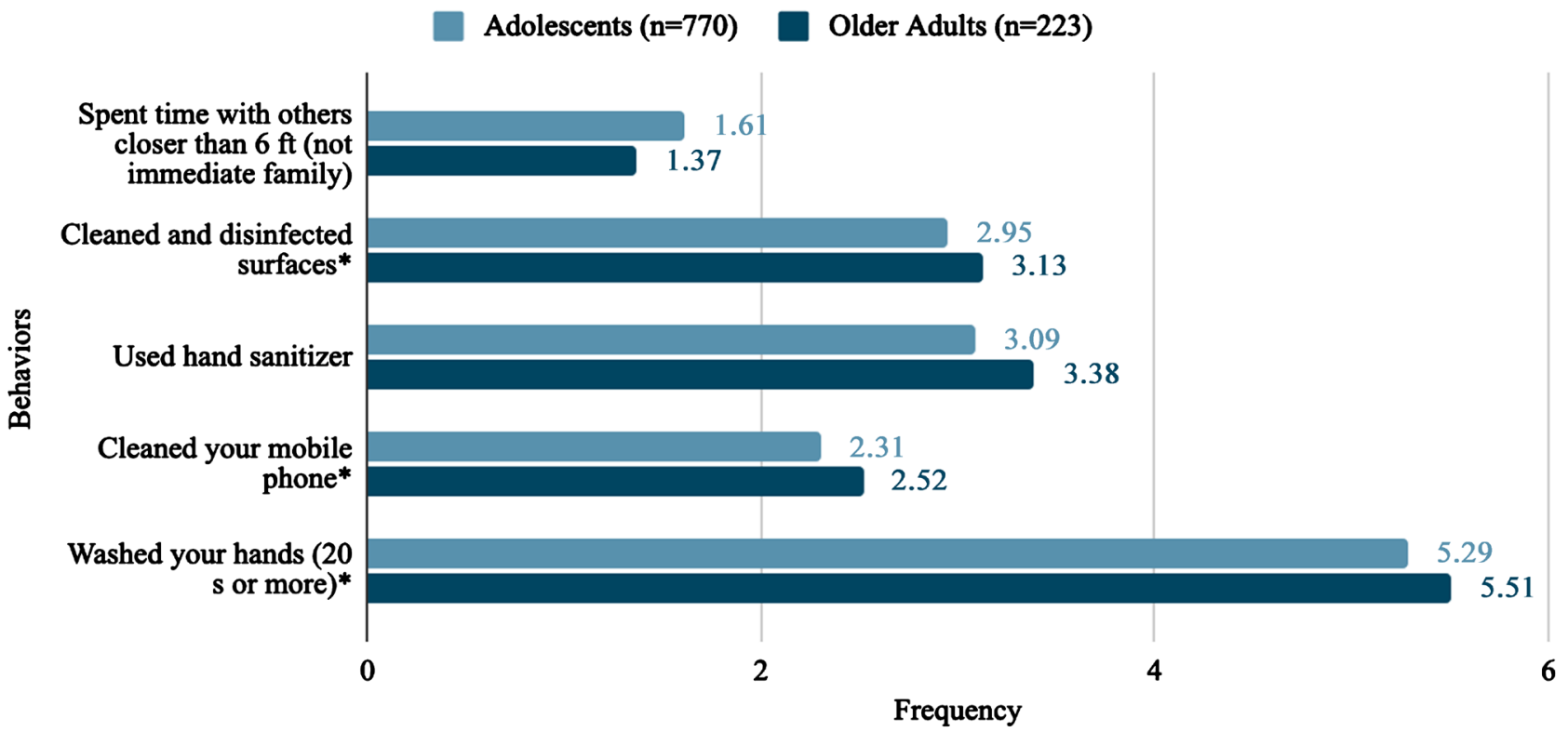

Note: Key-1 = not at all; $6=$ multiple times per day. ${ }^{*}$ Significantly different at the $\mathrm{p}<0.05$ level. (Note that Oosterhoff and Palmer [2] used the term "hoarding," we used "hoarding or stockpiling," yet these were not significantly different [1.71 and 1.73]).

Figure 2. Behavior frequency in the past week. 


\section{OPINIONS ON THE IMPORTANCE OF THESE BEHAVIORS}

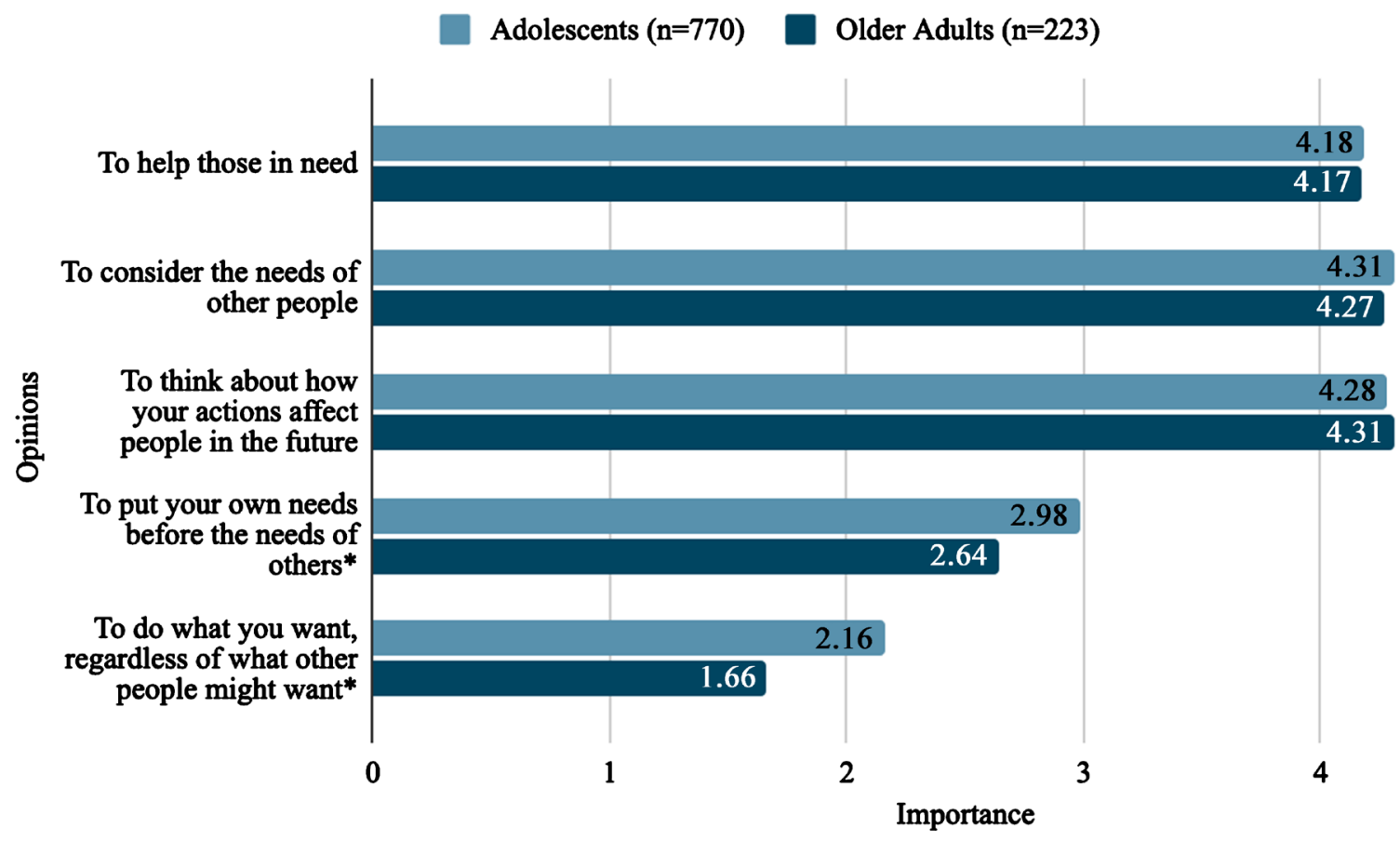

Note: Key $-1=$ Not important; $5=$ Extremely important; ${ }^{\star}$ Significant difference at the 0.01 level.

Figure 3. Opinions on the importance of these behaviors.

importance on this compared to adolescents (approximately. 5 mean difference).

Other Results (Older Generation)

Most older adult respondents (79\%) stated the virus had impacted their daily lives "much" or "a great deal." Only 9\% expressed that they had experienced a similarly challenging situation previously in their lives. When asked about the past week, 32\% worried about getting COVID-19 at least three times throughout the week, while $26 \%$ were not worried at all. More concern was shared about others (rather than themselves), with only $11 \%$ saying they were "not at all worried," while 59\% were worried about others at least three times during the past week. The elder respondents tended to agree with the protocols recommended by public health officials. Three-fourths (75\%) agreed or strongly agreed that masks should be worn in public, although only $17 \%$ agreed or strongly agreed that gloves need to be worn. Only $2 \%$ expressed that public health official guidance was an overreaction. Most (88\%) disagreed that the pandemic is "pitting generations against each other," and many (35\%) agreed that it is "bringing out the best in people." Worry about the pandemic's uncertain duration was common in this older group (92\%). Three-fourths (76\%) followed news coverage "much" or "a great deal," favoring television (78\%) and internet (64\%) sources.

\section{Hypotheses Testing}

Global factors were developed based on combining individual questions as shown in Table 1.

Hypothesis A: Men and women would display differing behaviors and attitudes. 
Table 1. Composite factors used for hypothesis testing.

\begin{tabular}{|c|c|}
\hline Name of Factor & Individual Questions Included \\
\hline $\begin{array}{l}\text { Seriousness of COVID: High scoring } \\
\text { participants did not view the virus as serious }\end{array}$ & $\begin{array}{l}\text { a. COVID-19 is being exaggerated } \\
\text { b. It is "just the flu" } \\
\text { c. It is not serious } \\
\text { d. It will have no major impact on the world } \\
\text { e. People are overreacting }\end{array}$ \\
\hline $\begin{array}{c}\text { Preventative Health Behaviors: High } \\
\text { scorers reported practicing these behaviors } \\
\text { more }\end{array}$ & $\begin{array}{l}\text { a. Social distancing (3 questions) } \\
\text { b. Disinfecting } \\
\text { c. Sanitizing hands } \\
\text { d. Wearing masks } \\
\text { e. Wearing gloves } \\
\text { f. Washing hands } \\
\text { g. Sanitizing phone }\end{array}$ \\
\hline $\begin{array}{c}\text { Conscientiousness: Higher scorers reported } \\
\text { a higher level of these aspects of } \\
\text { conscientiousness }\end{array}$ & $\begin{array}{l}\text { a. Worried about a loved one } \\
\text { b. Helping those in need } \\
\text { c. It is important to think about how our actions will } \\
\text { impact the future } \\
\text { d. Disagreement with: it is important to do what I } \\
\text { want, regardless of others }\end{array}$ \\
\hline $\begin{array}{l}\text { Fear: Higher scorers indicated that the } \\
\text { respondents were more fearful }\end{array}$ & $\begin{array}{l}\text { a. Worried that one will get the virus } \\
\text { b. Stressed about leaving the home } \\
\text { c. Generations are being pitted against one another } \\
\text { d. Worried about the length of quarantine in the US } \\
\text { e. Scared about shortages of food } \\
\text { f. Anxious about access to food }\end{array}$ \\
\hline
\end{tabular}

Note: These composite factors were used in secondary hypothesis testing (A.-E. above).

Using Mann-Whitney $U$ tests, men and women did not differ in their view of others, nor did they have differences in their health behaviors; women did view the pandemic as slightly more serious $(\mathrm{p}=0.001 ; \mathrm{Z}=-4.43)$. Also, women's responses indicated that they viewed themselves as more conscientious than men $(p=0.021 ; Z=-2.31)$. No other differences were found between the genders. Thus hypothesis A. regarding gender differences, such as females being more diligent about social distancing such as proposed by Oosterhoff and Palmer [2] was not supported.

Hypothesis B: Those who view the virus as more serious will be more likely to practice preventative health behaviors. This hypothesis was not supported.

Hypothesis C: Those who view themselves as more conscientious practice more preventative health behaviors. (Significant $\mathrm{p}=0.0001$ ) Spearman's $r h o=$ 0.249 . This hypothesis was supported.

Hypothesis D: Those who view the pandemic as more serious have more fear about the virus. (Significant, $\mathrm{p}=0.002$ ) Spearman's $r h o=0.217$.

Hypothesis E: Those who have a higher level of fear practice more preventa- 
tive health behaviors. (Significant, $\mathrm{p}=0.001$ ) Spearman's $r h o=0.274$.

None of the combined variables (health behaviors, seriousness, or level of fear) varied by education level or political leaning groups.

\section{Qualitative Analysis}

The research team used iterative content analysis to systematically summarize the content of the open-ended responses and allow for synthesis. Each of the three open-ended questions was analyzed separately. We assigned two analysts to each of the questions, and those team members independently read and inductively coded all responses and then met to compare, discuss, and develop code books for their respective open-ended item. For maximum clarity in coding, codebooks included code definitions, inclusion and exclusion criteria, and examples. One team member then coded all responses with the respective codebook, allowing for multiple codes to be applied to the same response when appropriate.

Thorough and accurate coding can ensure a high degree of reliability and promote the sharing of themes that do not reflect "personal ideological perspectives" [11]. To ensure reliable code application, a coder from another dyad (not familiar with the codebook) acted as a second coder, applying codes to the responses based on the codebook. We then measured inter-coder reliability using the Kuder-Richardson 20 (KR-20) reliability analysis as described by Davey et al. [11]. KR-20 for nine daily routine codes (two team members independently coding) was 0.875 , whereas the KR-20 for five social distancing codes was 0.767 (brought down by positive emotions [0.553]), and for six "final thoughts" codes 0.798 . These are acceptable to excellent [11].

\section{Changes in Daily Routine}

Two hundred and eleven of the older participants (95\% of the total) answered this question. Just about all acknowledged impacts on their daily life patterns since the March 2020 "stay at home" order. The most common change caused by the COVID-19 pandemic was the need to stay home with nearly half of the respondents reporting this adjustment to their daily routine. Said one: "I'm captive at home." Almost as many reported a change (usually a decline) in shopping, stating that they did this less and only for essential items, or relied on others to shop for them. The change in routine due to having to practice safe, preventative behaviors was also a common response. About a quarter mentioned fewer scheduled activities (especially leisure activities), although nearly as many stated they were doing more of some activities such as home projects (yardwork, reading, TV, and especially cooking), crafts, and walking outside. Only three respondents stated that there was no impact on their daily routine, and one stated that they had "excess" time with their partner.

In the current study, we did not specifically ask respondents about their ability to cope with the daily life changes wrought by the pandemic. However, nearly half of the respondents mentioned aspects of coping including learning, exercising, and communicating and engaging socially online (with $15 \%$ specifically 
mentioning Zoom). A fifth of the respondents (20\%) mentioned walking as a way to get out and exercise, often with their dogs. One respondent summarized how they were coping: "Staying very busy with vegetable gardening, beekeeping, jigsaw puzzles, listening to audiobooks from library, on-line Mah Jongg with friends while using Zoom video chat, and FaceTiming with daughters and grandbaby." A few quotes illustrate the changes in daily routine:

- "Whereas I rose at 5:30 a.m. weekdays to attend deep water aerobics classes, I now sleep in every day until I feel like getting up. And I walk 3 miles a day instead to keep my body moving well. I spend too much time on my digital devices, phone and computer. On the plus side, I am able to participate in selected Zoom meetings to engage with topics and people of my choice."

- "Cooking much more, not eating out....eating more sweets and carbs."

- "I’m lazier than ever. Knowing I'll have no drop in visitors makes it easier to skip chores. I read more. I use the phone more. I drink more wine more often than is good for me."

Several mentioned feeling distracted or otherwise unable to make productive use of time:

- "I am very, very inefficient now-takes me forever to make decisions, I muddle around the house never getting things done."

- "I find it is hard to concentrate for large chunks of time."

"All the time in the world and nothing gets done."

The most common expressions of the impact on mental health referenced loneliness or isolation:

- "I spend a lot of time alone. They closed the beaches and that upsets me."

- "Miss seeing my grandchildren. Terribly."

- "I know I'm fortunate that I can still do my grocery shopping and other errands, but I am lonely."

- "I am fortunate to have my husband, or I wouldn't even see anyone."

\section{Thoughts on Social Distancing}

An almost equal number (212) of participants shared their thoughts on social distancing. Over half addressed the losses and limitations they have endured due to "socially distancing" from others, yet several added their perspectives on the importance and necessity of the mandate. The respondents mentioned what they missed the most included seeing friends and family (and especially grandchildren). Hugs and intimate contact were mentioned as significant losses and one wrote: "Social distancing has kept a romance from progressing." Missed activities included book groups, craft groups, communal meals, church, exercise classes, socializing (in general), and celebrations (one even mentioned missing funerals).

Participants freely shared words and phrases related to negative emotions (e.g., anger, annoyance, boredom, anxiety, depression, fear, frustration, sadness, loneliness, fatigue, worry, and irritation), yet generally each of these individual feelings was only mentioned by a small percentage of respondents. Several 
people mentioned positive feelings (adjusting, increasing awareness, gratitude, feeling lucky, valuable spiritual healing, learning new things, staying busy, and feeling "privileged to be here"). A sense of acceptance and an awareness of the importance and necessity of the mandate was evident among about a quarter of the commenters, as illustrated by the following quotes.

- "I don't like it, but I feel it is very necessary. I'm lucky to be married-it's got to be so hard for single people."

- "It means I am doing all I can to prevent the spread of the disease and to hopefully eliminate a situation of not having enough medical personnel and supplies to treat those who will ultimately be affected."

- "I'm hoping social distancing will help save lives-including mine and my family's."

- "Actually, I always liked 'social distancing' way before now."

- "Intellectually understand the need but feel isolated."

Table 2 addresses other comments from the social distance question segment along with how many mentioned this. Notable quotes are also included. The most common lament was not being able to visit with or hug grandchildren (13\% of those who commented).

Although not asked as a direct question in the survey, participants did occasionally share why they were motivated to comply with social distancing. Curtailing the spread and saving lives/protecting others were the most commonly mentioned responses.

\section{Other Comments from Respondents}

The respondents shared many final comments when they were asked at the end of the survey, if they had any "other thoughts to share." These comments, from about two-thirds of the total respondents $(n=148)$, fit into the realms of concerns/worries/confusion, negative outcomes, and perhaps surprisingly, positive outcomes of the pandemic. Since so many respondents felt compelled to include additional (optional) comments, and these do not fit with any hypotheses, a few themes are worth sharing. The most frequent theme related to "concerns for the future," especially financial concerns and concern for others. One wrote,

Table 2. Other comments about social distancing.

\begin{tabular}{ll}
\hline Negative & Positive \\
\hline Hate/miss not seeing peoples' faces (4) & Grateful to have spouse/partner (5) \\
Not natural/not normal (2) & I have adapted well (3) \\
Pain in the ass (2) & I don't mind staying home (2) \\
Spouse has dementia which is depressing (1) & Getting more done (1) (home projects [1]) \\
Shopping is burdensome (1) & Nice to have family around (1) \\
Wearing mask is objectionable (1) & Social distancing does work (1) \\
Have lost deep connection with clients (1) & Has had no effect (1) \\
Can't wait until social distancing is no longer necessary (1) & Retirement makes this easier (1) \\
Being hard of hearing makes it more difficult (1) & Glad to be able to connect virtually (1)
\end{tabular}


"It has clearly exposed the inequities in our society in terms of healthcare, salary inequity, and race," while another added, "Health and economy need to be reasonably balanced." Although complaints about the government's response at the federal level were common, even more frequent were comments on the positive aspects of the pandemic and hope for the future. These comments included gratitude for the frontline workers (and for life in general) and an appeal to view the pandemic as a wake-up call. For example, one respondent shared "to not take life, people, treasures and values for granted; to learn the joy of living in the now moment, not live in the past or the future (and to) learn to trust others."

Several commented on the positive environmental impact of COVID-19. To illustrate, a respondent stated they were "fascinated by the impact the pandemic is having on the natural world...pollution has dramatically disappeared in some places. It's like our earth is taking a big sigh of relief." Hope for the future was a common theme, as one wrote: "I cautiously hope that it will stimulate at least some of the profound changes America needs in all sorts of areas: economic philosophy; environment; infrastructure; and all the 'isms' (racism; ageism; sexism, etc.)."

\section{Discussion}

Older adults primarily from the northeastern United States were surveyed concerning their attitudes and health behaviors in response to the COVID-19 pandemic in spring to mid-summer 2020. Respondents were mostly female (83\%), Caucasian (95\%), college educated (81\%), from households of 1 - 2 individuals (87\%), politically liberal (59\%), and financially secure (85\%). The sample is not representative of the population of older adults in the United States, in that it was more predominantly female, less diverse, and more liberal-leaning. Also, our respondents were comparatively highly educated. Only $38 \%$ of adults aged 65 and over in the US have college degrees [12], whereas $84 \%$ of the current respondents had 16 years of education or more, and the lowest educational attainment by any respondent was 10 years $(n=1)$. All other respondents had at least a high school education.

An inspiration for this study was a survey of teenagers concerning these COVID-19 topics by Oosterhoff and Palmer [2]. As specialists in aging, the author team was interested in comparing viewpoints across generations. Teenagers from the Oosterhoff and Palmer study differed significantly from our older respondents in each area, generally evidencing less concern and engagement. Our hypothesis that older adults would take the pandemic more seriously was confirmed. This could be explained by older age making the elders feel, rightly so, more vulnerable to the virus. This is consistent with findings from the Perrotta study [4]. However, although perceived risk may lead to more fear, and thus significant changes in behavior, these connections did not appear to be direct. In our elder study more fear was associated with more preventative behaviors as was self-reported higher degree of conscientiousness, yet those who deemed the 
virus to be more serious did not report behaving differently. Conscientiousness appeared to be more important than perceived risk, leading to the finding that both the elders and the youth studied reported similar levels of mitigating behaviors. This is a noteworthy finding that perceived severity level was not significantly associated with degree of preventative health behaviors. Could this be because so many of our older respondents viewed the virus as serious? Perhaps our group was rather homogeneous in their views and in their response patterns, thus making broad generalizations from this current study to older adults at-large problematic.

Overall, responses from both age groups evidenced a clear appreciation for the potential severity of the virus, a general willingness to follow public health guidance (e.g., mask wearing, social distancing) to avoid exposure, and a strong desire to keep up with news about the pandemic and related developments. We note similar levels of reported preventative behaviors by both age groups, even those that were statistically different (with elders slightly more compliant with CDC recommendations [1]) similar to the Seale et al. study [8]. Certainly, participants in either group may have been reporting higher levels of compliance with recommended health measures due to the well-documented tendency of people to select responses that are more socially acceptable, as noted by Larsen $e t$ al. [13] and seminally by Gordon [14]. While this effect would lead to inflated reports of socially acceptable behaviors, and it might also account for the similar levels across the study samples.

The current results demonstrated only minimal differences between men and women (with women only viewing the pandemic as slightly more serious, but no significant differences in behavior). This is an interesting finding because in the Perrotta study [4], women showed higher threat perception, lower confidence in healthcare system, and higher likelihood of adopting preventative behaviors. Females had a higher adoption rate for mask wearing than males in the US. Also, in the Seale et al. study [8], Australian females were more likely to report the uptake of both preventive and avoidance behaviors, consistent with studies during SARS and H1N1 pandemic influenza. Lastly, in the Wolf study [5], the threat of COVID-19 outbreak was rated as more serious by adults aged 70 years or older and by women. The current study may not have had enough male respondents to make definitive claims. Additional research assessing gender differences is needed.

While in the current study we did not find a difference in health behavior compliance among political groups (conservative, moderate, and liberal), political leanings and their influence on pandemic behaviors also could be explored further. Our finding about the lack of significant political influence is juxtaposed to the Callow et al. study [15] that demonstrated significant differences among political groups including both moderate and strong Republicans expressing lower intentions to follow social distancing and other preventive measures such as "stay-at-home" advisories. It does need to be noted, however, in the Callow et 
al. [15] study, while having similar numbers of respondents, there was a more balanced number of each political group. Clements [16], in an on-line survey of 1034 adults, found that self-identified Democrats had 30\% lower odds of attending large gatherings. However, surprisingly, the Democrats had 48\% lower odds of using medical masks compared to Republicans. However, the Clements study [16] was completed in March before mask wearing was highly recommended.

The qualitative analyses yielded rich information about the lived experience of our respondents in the time of this global Coronavirus (even though relatively few were directly impacted at the time of the study, up to July 2020). From the "Changes in Daily Routine" question, it is obvious that the COVID-19 pandemic has resulted in significant changes in daily routines. The most frequent responses involved more home-based activities as most of the respondents (from the northeastern USA) were complying with the stay-at-home mandate. Many expressed a loss of their routines and of typical face-to-face social gatherings, but others demonstrated a sense of resilience in managing to stay upbeat and engaged in activities beyond their usual or their pre-COVID typical routine. Coping skills such as getting outside to walk and increasing the use of technology to communicate were frequently mentioned. Exploring these and other coping mechanisms would also provide interesting topics for future research. One important question: how is the use of digital technologies associated with positive and negative aspects of coping, especially during the pandemic?

The current social distancing recommendations and the stay-at-home orders are intended to keep older adults safe, but social isolation, which has been strongly advised or even mandated, can come with the increased risk for cardiovascular, autoimmune, neurocognitive, and mental health problems including depression and anxiety [17]. Armitage and Nellums [18] describe how many non-technologically fluent older adults rely on face-to-face visits, day and community center venues, and places of worship for their social network, especially if they do not have any close friends or family. Preliminary studies in the time of the pandemic have found increased loneliness in older adults, with possible increases in depression [19] [20] [21]. On the other hand, Luchetti et al. [22] in a survey of 1545 adults in the USA did not find an increase in loneliness in March and April 2020 following the stay-at-home order, compared to in February before the order was given. Perhaps the increases in loneliness take longer to surface.

While the final tally of the impact of COVID-19 on the mental health of older adults has yet to be determined, a potential public health crisis, coined the "COVID-19 social connectivity paradox" [23], is looming and demands our immediate attention. Mitigating factors include increased outreach to vulnerable people virtually and over the telephone. For those who are not able to, or do not welcome, digital technology, an increased effort must be expended to enhance the desirability, the access, and ease of use of technology for communication. 
The majority of respondents shared optional comments about both the negative, and sometimes surprisingly positive, emotional consequences of the pandemic. People overwhelmingly felt the need to share these thoughts and feelings, as they were significant and impacted their lives beyond the physical. A sense of loss and longing came through, especially for seeing and touching loved ones and face-to-face encounters. However, several respondents "counted their blessings" and used the time to learn new things. Could this sense of adaptability and optimism be a trait that naturally develops through life experience, in older adults who are aging well? Other researchers have found similar themes among elders. For example, Brockie and Miller [24] found older adults who had lived through the floods in Brisbane, Australia, to be overall optimistic and resilient, a finding that they linked to increasing social capital with age and previous experience with life's difficult situations.

Not everyone in the current study reported positive outcomes; a few seemed overwhelmed with the current situation or reported the new-found time wasted (as they could not easily motivate themselves to get things done). This finding begs the question: Are additional psychosocial interventions to build social capital (including tangible and human resources) and to promote resilience (through cognitive behavioral therapy, such as suggested by Padesky and Mooney [25]) especially crucial in this current time of trauma?

An interesting deliberation occurred when discussing the motivation to comply with the social distancing recommendations. Respondents often mentioned that it "was necessary" and one important way to "curtail the spread." These simple quotes leave room for interpretation and can begin to be interpreted through the lens of moral reasoning [26]. When someone states social distancing is "necessary," this could be viewed as something that must be done to obey the law, or the rules, and avoid punishment (early stage of development) or it could be viewed as a late stage, universal principle that in a just society, we do what is in the best interest of others (even beyond ourselves). The term "necessary" can denote an obligation to take care of others in an altruistic way, but without further details, which the current study does not supply, we cannot be certain of the respondents' true underlying motivations. This finding lends impetus for future studies exploring the motivations of compliance among all age groups during this pandemic experience. Also, since Oosterhoff and Palmer [2] did not ask this open-ended question about motivations, we cannot compare the reasoning for compliance between the generations, even though the reported levels of compliance were often similar.

The other comments or final open-ended question revealed that the majority of respondents had additional thoughts to share. This is a time of introspection and learning; a difficult time with a few rays of sunshine. Respondents voiced concerns, more commonly for others rather than themselves, often related to family members, finances or the economy, and the fate of marginalized populations. In addition, a primary concern for many was the political state of the 
country and the extreme division being experienced at the time of the survey. Although this was not intended to be a political survey, life within a raging pandemic has become ever more political, and people felt compelled to vent their views of dismay as well as gratitude. Certainly, we cannot reach consensus on the overall view of older adults, as they are admittedly a heterogeneous group. However, some trends have become evident through the example quotes. Expressions of positivity were surprisingly frequent. These are related to hope for the future of the human race and the environment.

\section{Limitations and Future Directions}

This study has a number of limitations. The older respondents were individuals who had the time, the ability, and the motivation to complete an online survey, which may set them apart. Many were linked with UNE through our Legacy Scholars Program and also were more educated than the general population of similar-age peers. This sample reflects the attitudes of white, middle-class older adults in Maine and New England. The current sample was relatively small and rather homogeneous in their views, and therefore the results are not readily generalizable. Nonetheless, these views are worth sharing as a place to start.

Another limitation is that the timeframe for comparisons of the older respondents with the younger generation was not ideal (simultaneous and exact question comparisons would have been preferred). The timeframes of the adolescent survey and the elder survey were at least one month apart (although early, preliminary analyses comparing the two groups were not significantly different from subsequent later analyses). In addition, at the time of the survey, New England was relatively protected from the direct effects of the pandemic.

Certainly, specific explorations about the psychosocial impact of and reasoning underlying behaviors related to the pandemic will lead to more in-depth understanding of the psychological impacts of this wide-spread virus. We have only grazed the surface of the potential motivations behind the "why" people have reacted in the ways that they did. We also are only beginning to understand the ultimate mental health impact of the strict measures meant to keep older adults safe. Much more research, especially robust studies that are both quantitative and qualitative, will help us to better understand the mental health outcomes and human reasoning especially in unusual circumstances such as this time of COVID-19.

Finally, the pandemic is an evolving crisis and situation. The impact of this historical and unparalleled occurrence may change from day-to-day and be different for each person (or groups of people). This study offers a snapshot of attitudes and behaviors of a small group of older adults in a brief period of time and compares some of these behaviors and views with a nationwide group of adolescents. These limited results may not hold true in the future.

\section{Conclusions}

Respondents to this survey viewed the COVID-19 pandemic as serious, finding 
it necessary to be informed about, and worthy of personal actions to stay safe and prevent transmission. Most reported appreciation for the scientifically-based guidance and adherence (when it occurred) to the evidence-based preventative guidelines. These older adult respondents are not representative of the wider population, particularly in respect to education, diversity, and socioeconomic status. While attitudes about the seriousness of the pandemic may vary by age group, with elders feeling more vulnerable, the reported compliance levels tend not to be (very) significantly different. Future research could focus more on the psychological impact of the pandemic and the coping skills of different age groups. In addition, intervention studies that focus on positive coping skills, and the enhancement of technological communication, seem to be essential at this unprecedented time in our human history.

Since this research project was largely descriptive and exploratory in nature, the practical implications of these outcomes may not be direct or immediate. However, the COVID-19 pandemic, horrible and devastating as it has been, nonetheless has offered us the opportunity to explore intergenerational opinions and aspects of human nature (peoples' responses to a global pandemic) that simply were not part of our lives before 2020. This preliminary report of attitudes and behaviors lends itself not only to further study on a more global basis, but also provides important information for potential public health education and policies for differing age groups in light of our new world reality.

\section{Acknowledgements}

We wish to acknowledge and thank Michael R. Kohut, $\mathrm{PhD}$, of Maine Medical Center Research Institute, Portland, Maine, USA for his qualitative expertise and technical assistance.

\section{Conflicts of Interest}

The authors declare no conflicts of interest regarding the publication of this paper.

\section{References}

[1] Centers for Disease Control and Prevention (2020) Coronavirus (COVID 19). https://www.cdc.gov/coronavirus/2019-ncov

[2] Oosterhoff, B. and Palmer, C. (2020, March 23) Psychological Correlates of News Monitoring, Social Distancing, Disinfecting, and Hoarding Behaviors among US Adolescents during the COVID-19 Pandemic. https://doi.org/10.31234/osf.io/rpcy4

[3] Uscher-Pines, L., Maurer, J., Kellerman, A. and Harris, K.M. (2010) Healthy Young and Middle Age Adults: What Will It Take to Vaccinate Them for Influenza? Vaccine, 28, 7420-7422. https://doi.org/10.1016/j.vaccine.2010.08.095

[4] Perrotta, F., Corbi, G., Mazzeo, G., Boccia, M., Aronne, L., D’Agnano, V., Komici, K., Mazzarella, G., Parrella, R. and Bianco, A. (2020) COVID-19 and the Elderly: Insights into Pathogenesis and Clinical Decision-Making. Aging Clinical and Experimental Research, 1-10. https://doi.org/10.1007/s40520-020-01631-y 
[5] Wolf, M.S., Serper, M., Opsasnick, L., O’Conor, R.M., Curtis, L.M., Benavente, J.Y., Wismer, G., Batio, S., Eifler, M., Zheng, P. and Russell, A. (2020) Awareness, Attitudes, and Actions Related to COVID-19 among Adults with Chronic Conditions at the Onset of the US Outbreak: A Cross-Sectional Survey. Annals of Internal Medicine, 73, 100-109. https://doi.org/10.7326/M20-1239

[6] Daoust, J.F. (2020) Elderly People and Responses to COVID-19 in 27 Countries. PLoS ONE, 15, e0235590. https://doi.org/10.1371/journal.pone.0235590

[7] Canning, D., Karra, M., Dayalu, R., Guo, M. and Bloom, D.E. (2020, April 23) The Association between Age, COVID-19 Symptoms, and Social Distancing Behavior in the United States. https://doi.org/10.1101/2020.04.19.20065219

[8] Seale, H., Heywood, A.E., Leask, J., Steel, M., Thomas, S., Durrheim, D.N., Bolsewicz, K. and Kaur, R. (2020, June 23) COVID-19 Is Rapidly Changing: Examining Public Perceptions and Behaviors in Response to This Evolving Pandemic. https://doi.org/10.1101/2020.05.04.20091298

[9] Czeisler, M.É., Tynan, M.A., Howard, M.E., Honeycutt, S., Fulmer, E.B., Kidder, D.P., Robbins, R., Barger, L.K., Facer-Childs, E.R., Baldwin, G. and Rajaratnam, S.M. (2020) Public Attitudes, Behaviors, and Beliefs Related to COVID-19, Stay-at-Home Orders, Nonessential Business Closures, and Public Health Guidance-United States, New York City, and Los Angeles, May 5-12, 2020. Morbidity and Mortality Weekly Report, 69, 751. https://doi.org/10.15585/mmwr.mm6924e1

[10] Luo, Y., Cheng, Y. and Sui, M. (2021) The Moderating Effects of Perceived Severity on the Generational Gap in Preventive Behaviors during the COVID-19 Pandemic in the US. International Journal of Environmental Research and Public Health, 18, 2011. https://doi.org/10.3390/ijerph18042011

[11] Davey, J.W., Gugiu, P.C. and Coryn, C.L.S. (2010) Quantitative Methods for Estimating the Reliability of Qualitative Data. Journal of Multidisciplinary Education, 6, $140-162$.

[12] US Census Bureau (2017) Current Population Survey. https://www.equityinhighered.org/indicators/u-s-population-trends-and-education al-attainment/educational-attainment-by-age

[13] Larsen, M.V., Petersen, M.B. and Nyrup, J. (2020) Do Survey Estimates of the Public's Compliance with COVID-19 Regulations Suffer from Social Desirability Bias? Journal of Behavioral Public Administration, 3. https://doi.org/10.30636/jbpa.32.164

[14] Gordon, R.A. (1987) Social Desirability Bias: A Demonstration and Technique for Its Reduction. Teaching of Psychology, 14, 40-42. https://doi.org/10.1207/s15328023top1401 11

[15] Callow, M.A., Callow, D.D. and Smith, C. (2020) Older Adults' Intention to Socially Isolate Once COVID-19 Stay-at-Home Orders Are Replaced with "Safer-at-Home" Public Health Advisories: A Survey of Respondents in Maryland. Journal of Applied Gerontology, 39, 1175-1183. https://doi.org/10.1177/0733464820944704

[16] Clements, J.M. (2020) Knowledge and Behaviors toward COVID-19 among US Residents during the Early Days of the Pandemic: Cross-Sectional Online Questionnaire. JMIR Public Health and Surveillance, 6, e19161. https://doi.org/10.2196/19161

[17] Gerst-Emerson, K. and Jayawardhana, J. (2015) Loneliness as a Public Health Issue: The Impact of Loneliness on Health Care Utilization among Older Adults. American Journal of Public Health, 105, 1013-1019. https://doi.org/10.2105/AJPH.2014.302427 
[18] Armitage, R. and Nellums, L.B. (2020) COVID-19 and the Consequences of Isolating the Elderly. The Lancet Public Health, 5, e256. https://doi.org/10.1016/S2468-2667(20)30061-X

[19] Krendl, A.C. and Perry, B.L. (2020) The Impact of Sheltering in Place during the COVID-19 Pandemic on Older Adults' Social and Mental Well-Being. The Journals of Gerontology Series B: Psychological Sciences and Social Sciences, 76, e53-e58. https://doi.org/10.1093/geronb/gbaa110

[20] van Tilburg, T.G., Steinmetz, S., Stolte, E., van der Roest, H. and de Vries, D.H. (2020, August 5) Loneliness and Mental Health during the COVID-19 Pandemic: A Study among Dutch Older Adults. The Journals of Gerontology, Series B: Psychological Sciences and Social Sciences, 76, e249-e255. https://doi.org/10.1093/geronb/gbaa111

[21] Stolz, E., Mayerl, H. and Freidl, W. (2020) The Impact of COVID-19 Restriction Measures on Loneliness among Older Adults in Austria. https://doi.org/10.1101/2020.09.08.20190397

[22] Luchetti, M., Lee, J.H., Aschwanden, D., Sesker, A., Strickhouser, J.E., Terracciano, A. and Sutin, A.R. (2020) The Trajectory of Loneliness in Response to COVID-19. American Psychologist, 75, 897-908. https://doi.org/10.1037/amp0000690

[23] Smith, M.L., Steinman, L.E. and Casey, E.A. (2020) Combatting Social Isolation among Older Adults in a Time of Physical Distancing: The COVID-19 Social Connectivity Paradox. Frontiers in Public Health, 8, 403. https://doi.org/10.3389/fpubh.2020.00403

[24] Brockie, L. and Miller, E. (2017) Understanding Older Adults' Resilience during the Brisbane Floods: Social Capital, Life Experience, and Optimism. Disaster Medicine and Public Health Preparedness, 11, 72-79. https://doi.org/10.1017/dmp.2016.161

[25] Padesky, C.A. and Mooney, K.A. (2012) Strengths-Based Cognitive-Behavioural Therapy: A 4-Step Model to Build Resilience. Clinical Psychology \& Psychotherapy, 19, 283-290. https://doi.org/10.1002/cpp.1795

[26] Kohlberg, L. (1985) Kohlberg's Stages of Moral Development. In: Crain, W.C., Ed., Theories of Development, Prentice-Hall, London, 118-136. 